Clinical paper

\title{
Uncontrolled donation programs after out-of-hospital cardiac arrest. An estimation of potential donors
}

\section{Jose Maria Navalpotro-Pascual $^{\mathrm{a}, *}$, Alfredo Echarri-Sucunza ${ }^{\mathrm{b}}$, Alonso Mateos-Rodríguez ${ }^{\mathrm{c}}$,}

Francisco Peinado-Vallejo ${ }^{\mathrm{a}}$, Patricia Fernández del Valle ${ }^{\mathrm{d}}$, Daniel Alonso-Moreno ${ }^{\mathrm{e}}$, Carmen del Pozo-Pérez ${ }^{\mathrm{f}}$, María V. Mier-Ruiz ${ }^{\mathrm{g}}$, Jose Ignacio Ruiz-Azpiazu ${ }^{\mathrm{h}}$, José Bravo-Castello ${ }^{\mathrm{i}}$, Natalia Martinez-Cuellar ${ }^{\mathrm{j}}$, Antonia Sáez-Jiménez ${ }^{\mathrm{k}}$, Carmen López-Unanua ${ }^{1}$, Roberto Antón-Ramas ${ }^{\mathrm{m}}$, María del Carmen Escriche-López ${ }^{\mathrm{n}}$, Jose Manuel Giraldo-Sebastià ${ }^{\mathrm{o}}, \mathrm{M}^{\mathrm{a}}$ José García-Ochoa $^{\mathrm{p}}$, Enrique Martín-Sánchez ${ }^{\mathrm{q}}$, Diego Borraz-Clares ${ }^{\mathrm{r}}$, Marta Martínez Del Valle ${ }^{\mathrm{s}}$, Cristina Carriedo-Scher ${ }^{\mathrm{t}}$, Fernando Rosell-Ortiz ${ }^{\mathrm{u}}$

${ }^{a}$ SUMMA 112, Madrid, Spain

${ }^{\mathrm{b}}$ Servicio de urgencias extrahospitalarias de Navarra, Navarra, Spain

c Oficina regional Coordinacion de Trasplantes, Consejería de Sanidad, Comunidad de Madrid Facultad de Ciencias de la Salud, Universidad Francisco de Vitoria, Madrid, Spain

${ }^{\mathrm{d}}$ Hospital Virgen del Rocio, Sevilla, Andalucia, Spain

e Emergentziak-Emergencias, Osakidetza, Euzkadi, Spain

${ }^{\mathrm{f}}$ Emergencias Sanitarias, Castilla y León, Spain

g Servicio de Emergencias 061 Cantabria, Cantabria, Spain

${ }^{\mathrm{h}}$ Servicio de Urgencias y Emergencias 061, Spain

Emergencias sanitarias de Extremadura, Extremadura, Spain

${ }^{j}$ SAMU 061 Baleares, Islas Baleares, Spain

${ }^{\mathrm{k}}$ Servicio de Emergencias 061, Murcia, Spain

${ }^{1}$ Fundación Pública Urxencias Sanitarias 061, Galicia, Spain

m 061 e Instituto de Ciencias de la Salud, Aragón, Spain

${ }^{\mathrm{n}}$ SAMU, Emergencias Sanitarias, Comunidad Valenciana, Spain

- Sistema Emergencies Mediques, Catalunya, Spain

p SAMUR Protección Civil, Madrid, Spain

${ }^{q}$ Servicio de Urgencias Canario, Islas Canarias, Spain

${ }^{r}$ Servicio de Bomberos de Zaragoza, Aragón, Spain

${ }^{s}$ SAMU-Asturias, Asturias, Spain

${ }^{\mathrm{t}}$ Servicio de Urgencias y Emergencias, Castilla La Mancha, Spain

"Empresa Pública de Emergencias Sanitarias, Almería, Andalucia, Spain

\section{A R T I C L E I N F O}

\section{Article history:}

Received 1 August 2017

Received in revised form 21 November 2017 Accepted 24 November 2017

Available online $\mathrm{xxx}$

Keywords:

Out-of-hospital cardiac arrest Emergency medical services

Physician on board

Uncontrolled donation after cardiac death

\section{A B S T R A C T}

Objective

To determine the number of potential deceased organ donors from out-of- hospital cardiac arrest cases (OHCA) attended by public physician-led emergency medical services in Spain, based on data recorded in the nationwide Spanish OHCA Registry (OHSCAR). Material and methods

We analysed OHSCAR data on deceased OHCA patients in Spain during 13 months (1/10/2013 to 31/10/ 2014). Variables included age, sex, estimated OHCA time, cardiopulmonary resuscitation (CPR) start time and outcome. Inclusion criteria were: age 16-60 years, witnessed OHCA, no return of spontaneous circulation (ROSC) and time interval $<15$ min between OHCA occurrence and CPR initiation. Results

Of a total 8789 cases, 3290 met the age criteria; of these, CPR was not witnessed in 745 cases. Among the remaining 2545 patients, 141 were included in uncontrolled donation after cardiac death (uDCD) programs, 902 arrived at the hospital with ROSC, 64 arrived with ongoing CPR and 15 cases were lost to follow-up. Of the remaining 1423 without ROSC, CPR initiation time was not recorded in 454 cases and 398 did not meet the time criteria $<15$ min between OHCA and CPR initiation.

Finally, 571 met all the criteria and could have been potential donors. There were significant differences in the actual donors percentage from potential donors percentage between provinces with and without donor

\footnotetext{
* Corresponding author.

Email address: chemanp@gmail.com (J.M. Navalpotro-Pascual)
} 
programs $(141 / 322=43.8 \%$ versus $0 / 390=0 \%)$, but there were no differences in ROSC between the two types of provinces $(418 / 1320=31.7 \%$ versus $652 / 1970=33.4 \%)$.

Conclusions

Many potential donors are missed in current clinical practice. uDCD programs are few and underused even in a country with high rates of organs transplantation.

\section{Introduction}

Uncontrolled donation after cardiac death ( $\mathrm{uDCD}$ ) has become an emerging source of organ donation in recent years. The decline in traffic accidents and improvements in the care of patients with cerebrovascular and cardiovascular diseases has radically changed the organ donor patient profile [1,2]. In 2015, there were 1851 donors in Spain and 314 of these were DCD donors [3]. Of these, 95 (30\%) were considered uDCD (type IIa in the modified Madrid classification) [4].

$\mathrm{uDCD}$ represents a growing opportunity for organ procurement. As the number of brain death donors decreases, other ways have to be found so that the number of transplants does not decrease. The two ways currently being used are: live donor transplantation and uDCD $[5,6]$. The number of uDCD programs in Spain has increased and many provinces without such programs are considering establishing them.

The data show how uDCD programs in Spain generate multiple organs for recipient benefit [7]. However, uDCD figures have stagnated since 2012 when a record number of 134 donors was achieved. Interestingly, the number of $\mathrm{uDCD}$ programs has increased in recent years. From the time the first such program was launched in Spain in 1989 [8] until the year 2013, there have been seven autonomous regions with emergency medical services (EMS) participating in uDCD programs [2]. These programs have proven to be feasible in cities with widely varying numbers of inhabitants, which opens a door to the generalization of this strategy. In 2012, the National Transplant Organization (NTO) of Spain published a National Consensus Document [9] to standardize and promote the development of these programs, which was reinforced through a later agreement with the Spanish Society of Emergency Medicine [10]. The document set out inclusion and exclusion criteria for this type of donor. However, their final application depends on protocols between the receiving hospitals and the emergency medical services (EMS) that work with them, in accordance with their experience and each particular case. For these reasons, the criteria vary slightly between different communities.

In 2013, the Out of Hospital Spanish Cardiac Arrest Registry (OHSCAR) project was launched with the participation of public EMS from the 17 autonomous regions of Spain and two large municipal emergency services. The main objective of this project is to determine survival rates and neurological sequelae of EMS-treated patients suffering out-of-hospital cardiac arrest (OHCA) in our country. OHSCAR also provides data about patients who die in the field.

The objective of the present study was to evaluate the number of potential donors after cardiac death in regions with and without $\mathrm{UDCD}$ programs.

\section{Material and methods}

OSHCAR is a prospective registry of consecutive cases of OHCA trated by public EMS in Spain. Its methodology has been previously described [11]. Briefly, the registry continuously receives data from different EMS in the 17 autonomous regions of Spain and the municipal EMS in two large cities, Madrid and Zaragoza, which together represent all the out-of-hospital public services in Spain. They pro- vide emergency medical coverage for more than 40 million inhabitants and all mobile resources have physicians on board. OHSCAR includes all cases of OHCA where the EMS performed cardiopulmonary resuscitation (CPR) or post-resuscitation care after intervention by a first responder. Among others, the variables included in the registry are gender, age in years, estimated time of CA, CPR, time advanced $\mathrm{CPR}$ and resuscitation is initiated in situ, spontaneous recovery of circulation (ROSC), ongoing resuscitation during transfer to hospital and maintenance of resuscitation performed for possible inclusion in a uDCD program. Also recorded are variables such as the fact that the attending EMS participates in a uDCD program, the name of the receiving hospital and province. OHSCAR does not collect patient medical history variables.

The present study covered the period 1 October 2013-30 October 2014 (13 months).

The criteria for inclusion as UDCD were: age between 16 and 60 years old, the CA event was not recorded as "NOT witnessed", the time of CA and the start time of advanced CPR were known, and the time window between these times was not greater than $15 \mathrm{~min}$. Exclusion criteria were: the presence of ROSC, ongoing CPR to try and achieve ROSC, during transfer to hospital, and the absence of a record describing the patient's final outcome. We cannot collect other exclusion criteria such as judicial issues or patient comorbidities which may prevent the inclusion of a case in a uDCD program.

We described and compared the number and percentage of eligible cases in provinces with and without $\mathrm{uDCD}$.

\section{Statistical analysis}

We performed a descriptive analysis of quantitative variables using measures of central tendency and dispersion. For qualitative variables, the distribution of absolute and relative frequencies was used. Quantitative variables were compared using Student's $t$-test after verifying the normality of variable distribution with the Kolmogorov-Smirnov test. For categorical variables, we used contingency tables and chi2 tests, as appropriate. Differences with a $p$ value of less than 0.05 were considered statistically significant. All statistical analyses were performed using SPSS version 15.0.

\section{Results}

This 13-month study included a total of 8789 patients with CA, median (IQR) age $66(53-77)$ years, $72.1 \%$ men.

Of the total, 3290 (37.4\%) patients met the age criterion; of these, CPR was not witnessed in 745 cases. Of the remaining 2545 patients, $902(35.7 \%)$ arrived at the hospital with ROSC, 64 (2.5\%) arrived with ongoing CPR during the transfer, $141(5.6 \%)$ cases were included in uDCD programs and 15 cases were lost to follow-up. A total of 1423 $(56.2 \%)$ patients were declared dead at the scene. Of these, we excluded $454(31.9 \%)$ cases because of failure to record the time of the CA event and/or the time of initiating CPR, and 398 (28.0\%) patients who did not meet the time-window criterion (interval $<15 \mathrm{~min}$ between the OHCA event and initiation of advanced CPR). Finally, 571 patients $(40.1 \%)$ fulfilled all the inclusion criteria as potential uDCD. 
The results, according to whether the different provinces had an uDCD program or not, are shown in Table 1. There were significant differences between the two populations. This was not the case of the ROSC rate but rather with other inclusion criteria such as date completion times, ongoing CPR and patients declared dead at the scene.

In the provinces with a uDCD program, there were 1320 patients who met the age criteria but the CA event was not witnessed in 358 cases. Of the remaining 962 cases, $455(47.3 \%)$ were declared dead at the scene. Of this group, the time of the CA event or the time of CPR initiation was unknown in 154 cases, and the CA- CPR time interval was exceeded in 120 cases. Finally, 181 patients met all the inclusion criteria to be included in a uDCD protocol (Fig. 1).

In the provinces without a uDCD program, there were 1970 patients who met the age criteria but the CA event was not witnessed in 387. Of the remaining 1583 cases, 968 patients were declared dead at the scene. Of this group, the time of the CA event or the time of CPR initiation was unknown in 300 cases, and the CA- CPR time interval was exceeded in 278 cases. Finally, 390 patients met all the inclusion criteria for inclusion in the uDCD protocol (Fig. 1).

\section{Discussion}

Our review provides an overview of deceased organ donors from an EMS perspective. In a recent article, Cheetham et al. [12], explored the possibility of obtaining donors from a tertiary hospital perspective and potential donations from patients admitted after ROSC who finally die. In our study, donors are obtained after resuscitation failure [13] which focuses the efforts at the first stage, the pre- hospital setting.

The number of potential uDCD donors was 571, which represents one in every 2.5 OHCA patients who are declared dead at the scene aged between 16 and 60 years and whose CA event was witnessed. This quadruples the number of patients included in UDCD programs (141). Most of these potential donors suffered fatal OHCA in provinces without established donation programs; however, a significant number of cases occurred in areas with active uDCD programs (Table 2).

The comparison between provinces with and without uDCD programs presents some differences that seem logical. Fundamentally there is no difference in the percentage of patients who achieve

Table 1

Distribution of patients meeting age criteria by province with and without uncontrolled donation following cardiac death programs.

\begin{tabular}{|c|c|c|c|c|}
\hline & TOTAL & $\begin{array}{l}\text { Provinces with } \\
\text { uDCD program }\end{array}$ & $\begin{array}{l}\text { Provinces without } \\
\mathrm{uDCD} \text { program }\end{array}$ & $\begin{array}{l}P \\
\text { value }\end{array}$ \\
\hline $\mathrm{N}$ & 3290 & 1320 & 1970 & \\
\hline Male sex $(\%)$ & $\begin{array}{l}2541 \\
(77.3 \%)\end{array}$ & $1038(78.8 \%)$ & $1503(76.4 \%)$ & 0.059 \\
\hline Witnessed OHCA (\%) & 2345 & $915(69.3 \%)$ & $1430(72.6 \%)$ & 0.000 \\
\hline ROSC & $\begin{array}{l}1070 \\
(32.7 \%)\end{array}$ & $418(31.7 \%)$ & $652(33.4 \%)$ & 0.170 \\
\hline Ongoing CPR & $\begin{array}{l}79 \\
(2.4 \%)\end{array}$ & $46(3.5 \%)$ & $33(1.7 \%)$ & 0.001 \\
\hline Declared dead at scene & $\begin{array}{l}1984 \\
(60.6 \%)\end{array}$ & $714(54.1 \%)$ & $1270(65.0 \%)$ & 0.000 \\
\hline Donors & $\begin{array}{l}141 \\
(4.3 \%)\end{array}$ & $141(10.7 \%)$ & $0(0.0 \%)$ & 0.000 \\
\hline $\begin{array}{l}\text { Times registered (both): } \\
\text { Collapse and start ALS }\end{array}$ & $\begin{array}{l}2046 \\
(62.2 \%)\end{array}$ & $770(58.3 \%)$ & $1270(62.2 \%)$ & 0.000 \\
\hline $\begin{array}{l}\text { Collapse- start ALS } \\
\text { interval } \\
<15 \text { min }\end{array}$ & $\begin{array}{l}1055 \\
(57.7 \%)\end{array}$ & $415(61.1 \%)$ & $640(55.7 \%)$ & 0.013 \\
\hline
\end{tabular}

UDCD: uncontrolled donation after cardiac death; ROSC: recovery of spontaneous circulation; OHCA: out of hospital cardiac arrest; CPR: cardiopulmonary resuscitation ALS: advanced life support CA: cardiac arrest.
ROSC. There is a significant difference in declared dead at the scene cases, as well as in the proportion of ongoing CPR, probably due to a higher habit of maintaining ALS during relocation as required by uDCD programs. Differences in time recording are difficult to pinpoint, although we think they may be related to the recording systems of each EMS itself.

Upon analysing the results obtained in provinces that do have a uDCD program, we observed that the number of actual donors was 141, while the number of potential donors who were not included in $\mathrm{uDCD}$ programs was 181 . The number of potential donors is the absolute maximum that could have been achieved. If we add them to the real donors, there are 322 in provinces that have a UDCD program.

These potential donors met the basic age and time criteria, but we know nothing about other criteria such as biological aspects (bleeding lesions, having a malignant neoplastic disease, suspected infectious contagious disease etc.), logistics, refusal by the family, or simply that the EMS team attending a victim of OHCA did not consider the possibility of inclusion in a donation program. These uDCD programs start in the pre-hospital setting, so their success depends on the motivation of the EMS to improve the inclusion of eligible candidates. It is necessary to know the thoughts and attitudes of EMS professionals in approaching uDCD [14]. We have to work on all the ethics concerns that professionals can feel as problems when making immediate decisions in the field as to the inclusion of a patient in such a program. We have to give them tools and skills to facilitate subsequent family decisions $[15,16]$. Pre-hospital emergency teams should be instructed to minimize the loss of potential donors.

In those provinces where no such program exists, the number of potential donors was significantly higher. There were 390 cases declared dead at the scene, aged between 16 and 60 years, and the time window between CA and CPR initiation was less than $15 \mathrm{~min}$.

But in these theoretical calculations, we only included cases with known CA and CPR times. A large number of cases were lost because one or both of those times were not known. In the provinces with a uDCD program, 181 of 301 cases $(60.1 \%)$ met the CA-CPR time window of less than $15 \mathrm{~min}$. Upon extrapolating the data, it could be assumed that of the 154 cases with unknown CA or CPR time, the time window $<15$ min would be met in approximately 92 cases. If the same percentage is applied in this group $(23.7 \%)$, we can estimate 22 potential donors missed.

If this calculation is made for the provinces without a uDCD program, the previously mentioned 390 cases should be added to those excluded due to unknown CA-CPR times. If out of 668 cases, the CA-CPR time was known to be less than 15 min in 390 cases $(58.4 \%)$, there would be about 175 cases falling within the $15 \mathrm{~min}$ time limit after extrapolating these results to the 300 cases where one of the times is unknown. If $23.7 \%$ were candidate donors, another 41 potential donors would be lost.

\section{Limitations of the study}

This was a retrospective study based on a nationwide registry in which not only were there the typical limitations of a registry, but also unknown patient medical histories. Certain data in the medical history may disqualify a candidate f or donation, despite meeting the inclusion criteria. The registry does not record other possible specific circumstances of cases not included in active donation programs, such as judicial issues or patient comorbidities, which could be reasons for exclusion. There is another important limitation, which is the proportion of cases excluded due to a failure to record the time of the $\mathrm{CA}$ event and/or initiation of resuscitation. This is a limitation to be 


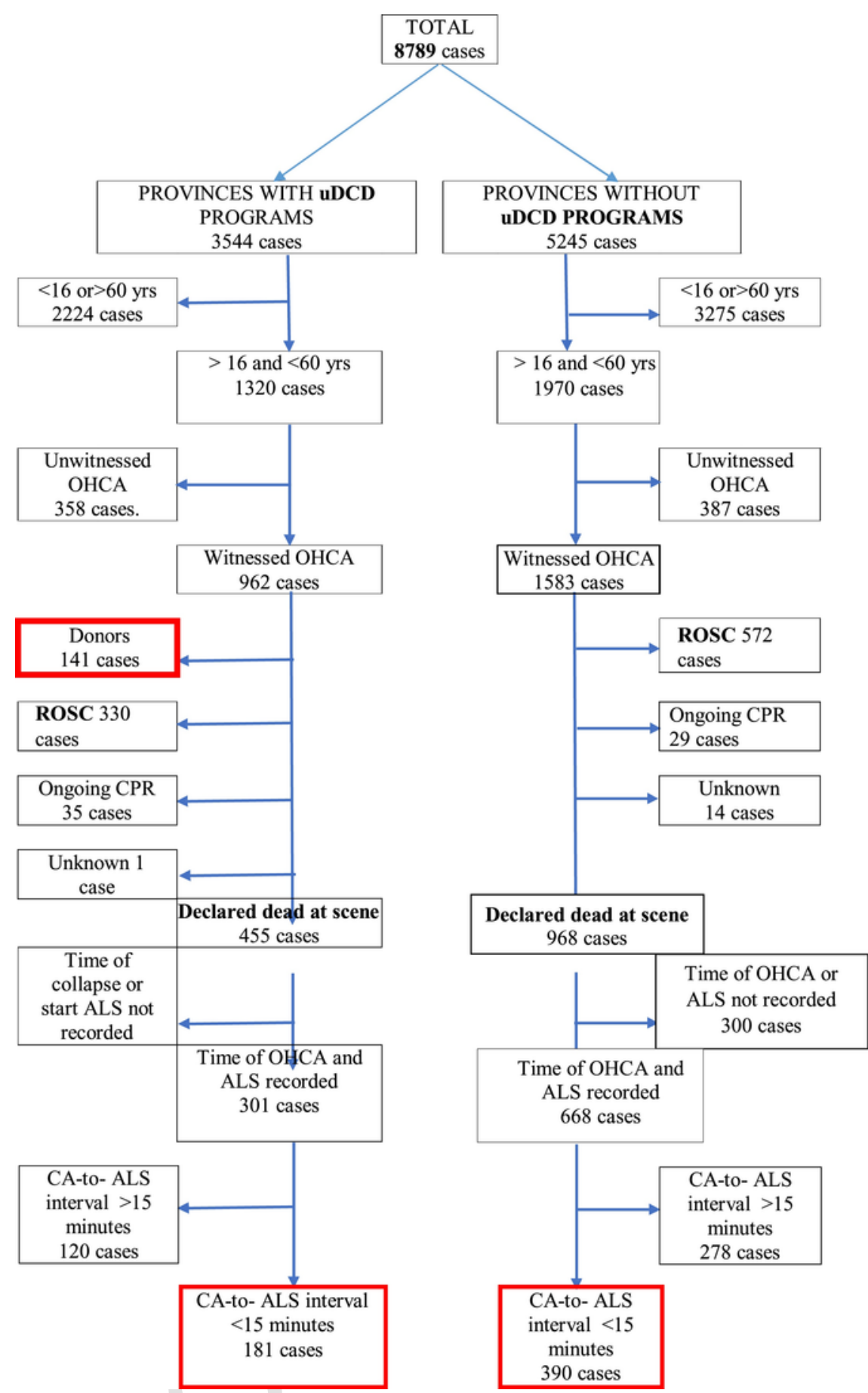

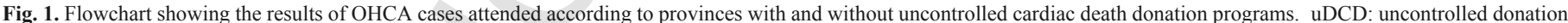

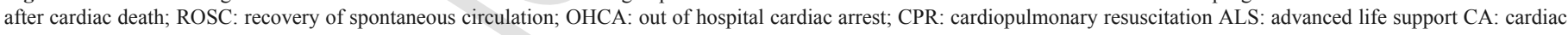
arrest.

taken into account when using records as quality tools. In addition, these cases fulfilled all the other inclusion criteria such as age and witnessed CA, and it is likely that some were attended within $15 \mathrm{~min}$ of the event. These are extrapolated data and can influence any final estimation. On the other hand, it may also suggest that the theoretical calculations made, although important, probably underestimate the real potential of these $\mathrm{uDCD}$ programs. The balance is certainly not clear.
Thus, 141 donors were obtained out of a total of 8789 OHCA patients. However, the maximum number of potential donors with the calculations done could have been close to $9 \%$ of the patients attended; in other words, almost 800 possible donors.

There is increasing interest in how EMSs approach resuscitation of patients with no real possibilities of survival [17]. Following this concern, the present study highlights that $\mathrm{UDCD}$ programs are underused even in a country with such high figures in organ transplanta- 
Table 2

Emergency services, provinces and hospitals participating in an uncotrolled donation after cardiac death program.

\begin{tabular}{|c|c|c|c|}
\hline Autonomous Community & $\begin{array}{l}\text { Emergency } \\
\text { service }\end{array}$ & Province & Hospital \\
\hline Andalucía & EPES-061 & $\begin{array}{l}\text { Granada } \\
\text { Sevilla }\end{array}$ & $\begin{array}{l}\text { Virgen de las Nieves } \\
\text { Virgen del Rocío }\end{array}$ \\
\hline Cantabria & 061 Cantabria & Cantabria & Marqués de Valdecilla \\
\hline Cataluña & SEM Cat & Barcelona & Clínic Hospital \\
\hline Valencian Community & SAMU & Alicante & San Joan Alicante \\
\hline Galicia & 061 & A Coruña & A Coruña \\
\hline $\begin{array}{l}\text { AutonomousCommunity } \\
\text { of Madrid }\end{array}$ & SUMMA 112 & Madrid & Clínico San Carlos \\
\hline & & & Doce de Octubre \\
\hline Madrid (City) & SAMUR-PC & Madrid & Clínico San Carlos \\
\hline Basque Country & $\begin{array}{c}\text { Emergencias } \\
\text { Osakidetza }\end{array}$ & $\begin{array}{l}\text { San } \\
\text { Sebastián }\end{array}$ & $\begin{array}{l}\text { Complejo Hospitalario } \\
\text { Donosti }\end{array}$ \\
\hline
\end{tabular}

EPES: Empresa Pública de Emergencias sanitarias; SEM Cat: Sistema d'Emergències Mèdiques de Cataluña; SAMU: Servicio de Ayuda Médica Urgente; SUMMA 112 Servicio de Urgencias Médicas.

tion. It is another multifactorial approach [18] to reducing the number of patients on waiting lists for organ transplantation.

\section{Conflict of interest statement}

On behalf of all the authors of the mentioned manuscript, Dr Navalpotro-Pascual declared nothing to disclose.

\section{Acknowledgements}

The authors wish to thank all dispatch centres, ambulance services and first responders for their help in ongoing data collection.

The Registry was funded by a public research grant from the Spanish Ministry of Health (Instituto de Investigación de Salud Carlos III, Fondo de Investigaciones Sanitarias, exp. number PI12-01912 and PI12/02309) and co-funded by a research grant from the European Commission.

\section{References}

[1] Activity report of 2015 year from the Spanish National Tarnsplant Organization (accessed on 28.03.17, at: http://www.ont.es/infes/Memorias/ Memoria\%20donantes\%202015.pdf).

[2] A.L. Caplan, Finding a solution to the organ shortage, CMAJ188 (2016) 1182-1183.

[3] Non-heart-beating report, 2015 Spanish National Tarnsplant Organization. (accessed on 28.03.17, at:) http://www.ont.es/infesp/Memorias/INFORME\%20DONACIÓN\%20EN\%20ASISTOLIA\%202015.pdf.
[4] J.M. Pérez-Villares, Non-heart-beating donation, Cuad Med Forense 21 (1-2) (2015) 43-49.

[5] R. Matesanz, B. Domínguez-Gil, E. Coll, B. Mahíllo, R. Marazuela, How Spain reached deceased organ donors per million population, Am J Transplant (2017) https://doi.org/10.1111/ajt.14014.

[6] R.J. Johnson, L.L. Bradbury, K. Martin, J. Neuberger, UK Transplant Registry. Organ donation and transplantation in the UK-the last decade: a report from the UK national transplant registry, Transplantation15 (97 (Suppl 1)) (2014) S1-S27.

[7] A. Mateos Rodríguez, J. Cepas Vázquez, J. Navalpotro Pascual, M. Martín Maldonado, C. Barba Alonso, L. Pardillos Ferrer, et al., Pre-hospital non-heart-beating donors; 4 yearsí experience of the SUMMA 112 emergency service, Emergencias 22 (2010) 96-100.

[8] A.I. Sánchez-Fructuoso, D. Prats, J. Torrente, M.J. Pérez-Contín, C. Fernández, J. Alvarez, et al., Renal transplantation from non-heart beating donors: a promising alternative to enlarge the donor pool, J Am Soc Nephroll1 (2) (2000) $350-358$.

[9] Spanish National Tarnsplant Organization. Non-heart-beating Donation in Spain Current situation and recommendations. Consensusstatement 2012. (accessed on 28.03.17), at: http://www.ont.es/infesp/DocumentosDeConsenso/ DONACIÓN\%20EN\%20ASISTOLIA\%20EN\%20ESPAÑA.\%20SITUACIÓN\%20ACTUAL\%20Y\%20RECOMENDACIONES.pdf

[10] F. Martínez Soba, N. Masnou Burrallo, G. De la Rosa Rodríguez, J. Povar Marco, Emergency department staff and the organ donation process: recommendations from the joint working group of the National Transplant Organization and the Spanish Society of Emergency Medicine (ONT-SEMES), Emergencias 28 (2016) 193-200.

[11] F. Rosell-Ortiz, X. Escalada-Roig, P. Fernandez Del Valle, L. Sanchez-Santos, J.M. Navalpotro-Pascual, A. Echarri-Sucunza, et al., Out-of-hospital cardiac arrest (OHCA) attended by mobile emergency teams with a physician on board. Results of the Spanish OHCA Registry (OSHCAR), Resuscitation113 (2016) 90-95.

[12] O.V. Cheetham, M.J. Thomas, J. Hadfield, F. O'Higgins, C. Mitchell, K.D. Rooney, Rates of organ donation in a UK tertiary cardiac arrest centre following out-of-hospital cardiac arrest, Resuscitation 101 (2016) 41-43.

[13] J.J. Egea-Guerrero, L. Martin-Villen, Z. Ruiz de Azua-Lopez, Organ donation process after unsuccessful cardiopulmonary resuscitation, Med Clin (Barc) 10 (2017) 430 .

[14] J. Povar Marco, M.A. Javierre Loris, C. Garcés Sanjosé, J.I. Sánchez Miret, Role of the hospital emergency department staff in the organ donation process: opinions of professionals working in the Spanish autonomous community of Aragon, Emergencias27 (2015) 46-49.

[15] J.M. Pérez Villares, R. Lara Rosales, E. Gil Piñero, E. Bravo Escudero, F. Alarcos Martínez, B. Domínguez-Gil, Ethics in approaching families about organ donation from patients in out-of-hospital asystole, Emergencias 28 (2016) 55-61.

[16] M. Puig Campmany, F. Caballero, J. Ris Romeu, J. Leal, S. Benito Vales, El profesional de urgencias, la limitación de tratamiento de soporte vital y las opciones de donación, Emergencias 28 (2016) 425-426.

[17] P. Jabre, W. Bougouin, F. Dumas, P. Carli, C. Antoine, L. Jacob, et al., Early identification of patients with out-of-hospital cardiac arrest with No chance of survival and consideration for organ donation, Ann Intern Med 165 (11) (2016) 770-778.

[18] P.E. Morrissey, A.P. Monaco, Donation after circulatory death: current practices, ongoing challenges, and potential improvements, Transplantation 97 (3) (2014) 258-264. 